\title{
Laparoscopic Approach in Surgical Staging of Endometrial Cancer
}

\section{Abordagem laparoscópica no estadiamento cirúrgico do carcinoma do endométrio}

\author{
Mariana Mouraz ${ }^{10}$ Cátia Sofia Ferreira ${ }^{2}$ Sónia Gonçalves ${ }^{2}$ Nuno Nogueira Martins ${ }^{2}$ \\ Francisco Nogueira Martins ${ }^{2}$ \\ ${ }^{1}$ Department of Obstetrics and Gynecology, Hospital Dr. José de \\ Almeida, Cascais, Portugal \\ 2 Department of Obstetrics and Gynecology, Centro Hospitalar \\ Tondela, Viseu, Portugal
Address for correspondence Mariana Mouraz, MD, Departamento de Ginecologia e Obstetrícia, Hospital Dr. José de Almeida, Praceta Filinto Elísio, N 10, RC B. 2790-069 Carnaxide, Portugal
(e-mail: mariana_mouraz@hotmail.com).

Rev Bras Ginecol Obstet 2019;41:306-311.

\begin{abstract}
Keywords

- endometrial neoplasms

- laparoscopy

- neoplasm staging

- hysterectomy

- lymph node excision
\end{abstract}

Resumo
Objective To compare laparoscopy with laparotomy for surgical staging of endometrial cancer.

Methods A cohort of women with preoperative diagnosis of endometrial cancer who underwent surgical staging was retrospectively evaluated. The main study end points were: morbidity and mortality, hospital length of stay, perioperative adverse events and recurrence rate. Data analysis was performed with the software SPSS V25 (IBM Corp., Armonk, NY, USA), categorical variables using a Chi-square and Fisher test, and continuous variables using the Student $t$-test.

Results A total of 162 patients were analyzed. 138 patients met the inclusion criteria, 41 of whom underwent staging by laparoscopy and 97 by laparotomy. Conversions from laparoscopy to laparotomy happened in 2 patients (4.9\%) and were secondary to technical difficulties and poor exposure. Laparoscopy had fewer postoperative adverse events when compared with laparotomy ( $7.3 \%$ vs $23.7 \%$, respectively; $p=0.005$ ), but similar rates of intraoperative complications, despite having a significantly longer operative time (median, 175 vs 130 minutes, respectively; $p<0.001$ ). Hospital stay was significantly lower in laparoscopy versus laparotomy patients (median, 3 vs 7 days, respectively; $p<0.001$ ). No difference in recurrence or mortality rates were observed.

Conclusion Laparoscopic surgical staging for endometrial cancer is feasible and safe. Patients have lower postoperative complication rates and shorter hospital stays when compared with the approach by laparotomy.

Objetivo Comparar a abordagem laparoscópica com a laparotômica no estadiamento cirúrgico do carcinoma do endométrio.

(1) Mariana Mouraz's ORCID is https://orcid.org/0000-0003-4105-

2432.

received

November 14, 2018

accepted

March 19, 2019
DOI https://doi.org/

$10.1055 / \mathrm{s}-0039-1688461$.

ISSN 0100-7203.
Copyright $\odot 2019$ by Thieme Revinter

Publicações Ltda, Rio de Janeiro, Brazil
License terms

(c) (1) 


\section{Palavras-chave \\ - neoplasias do endométrio \\ - laparoscopia \\ - estadiamento de neoplasias \\ - histerectomia \\ - excisão de gânglio linfático}

Métodos Avaliação retrospectiva de uma coorte de mulheres com diagnóstico préoperatório de cancro do endométrio submetida a estadiamento cirúrgico. As principais variáveis do estudo foram: morbilidade e mortalidade, tempo de internamento hospitalar, eventos adversos peri-operatórios e taxa de recorrência. A análise dos dados foi realizada com o programa SPSS v25 (IBM Corp, Armonk, NY, EUA), para as variáveis categóricas utilizou-se o teste do Qui-quadrado e o teste de Fisher, e para as variáveis contínuas o teste $t$ de Student.

Resultados A amostra foi constituída por 162 doentes. 138 pacientes preencheram os critérios de inclusão, 41 das quais foram submetidas a estadiamento por laparoscopia e 97 por laparotomia. As conversões de laparoscopia para laparotomia ocorreram em 2 doentes $(4,9 \%)$ e foram secundárias a dificuldades técnicas e má exposição. A laparoscopia teve menos eventos adversos pós-operatórios quando comparada à laparotomia (7,3\% versus $23,7 \%$, respectivamente; $p=0,005)$, mas taxas semelhantes de complicações intraoperatórias, apesar do tempo operatório significativamente maior (mediana 175 a 130 minutos, respetivamente; $p<0,001$ ). A permanência hospitalar foi significativamente menor na abordagem laparoscópica (mediana de 3 versus 7 dias, respectivamente; $p<0,001$ ). Não houve diferenças nas taxas de recorrência ou mortalidade.

Conclusão O estadiamento cirúrgico laparoscópico para carcinoma do endométrio é exequível e seguro. As doentes apresentam uma menor taxa de complicações pósoperatórias e tempo de internamento mais curto quando comparados aos da abordagem por laparotomia.

\section{Introduction}

Endometrial cancer (EC) is the sixth most common cancer in women worldwide and the most common gynecologic malignancy in developed countries. ${ }^{1,2}$ EC occurs mainly in postmenopausal women, with a peak incidence between 55 and 60 years of age. ${ }^{3}$ Women have a $2.5 \%$ lifetime risk of developing EC, and it is estimated that half million cases will be diagnosed worldwide by 2035. 1,4

Most cases of EC are diagnosed at an early stage, when the disease is more likely to be surgically treated with the best outcomes. ${ }^{3,5}$ The prognosis is determined primarily by disease stage and histology. Based upon the International Federation of Gynaecologists and Obstetricians (FIGO) criteria, EC is surgically staged. ${ }^{6,7}$ Complete surgical staging includes peritoneal cytology, exploration of the peritoneal cavity, extrafascial total hysterectomy, bilateral salpingo-oophorectomy, as well as pelvic and paraaortic lymphadenectomy in selected patients. ${ }^{6}$ The advantages of surgical staging lie in the diagnosis, prognosis, and proper triage of patients for adjuvant therapy. ${ }^{5,8}$ The surgical procedure is still associated with morbidity, long hospital stay, intraoperative and postoperative adverse events. ${ }^{9}$

The traditional surgical approach to EC staging is by laparo tomy. ${ }^{10,11}$ Alternative approaches may be appropriate in low risk patients. Over the past two decades, randomized controlled trials comparing laparoscopy and laparotomy staging with significant advantages over laparotomy have been conducted, especially in the reduction of perioperative morbidity. $3,11-13$
Laparoscopic staging surgery for patients with EC has been performed in Viseu (at a tertiary Portuguese center) since 2009 and more routinely since 2012; in this study, the authors intend to assess the safety and morbidity rate associated to the surgical staging of EC performed by either laparoscopy or laparotomy.

\section{Methods}

The present retrospective cohort study included all women with diagnosis of EC who were submitted to surgical staging between January 1st, 2012, and January 31st, 2018 at Hospital de São Teotónio, -in Viseu, Portugal.

The primary outcome of the study were surgical complications. Other end points included laparoscopy conversion to laparotomy, length of hospital stay after surgery, operative time, recurrence-free survival and survival.

Eligibility requirements were: preoperative diagnosis of EC and a surgical intervention that included, at least, a total hysterectomy and bilateral salpingo-oophorectomy, as advised for FIGO IA stages.

The research protocol was approved by the Institutional Ethics Committee before the study began. As the study was based on a retrospective analysis of existing administrative and clinical data, the board waived the requirement for informed consent. Demographic, preoperative, intraoperative, and postoperative data were retrieved from patient medical records.

Surgical stage was determined according to the rules of FIGO published in 2009 and the histological classification by 
the World Health Organization (WHO) criteria, published in 2014. ${ }^{3,14}$

Surgical approach was a decision of the operating surgeon, according to the best interest of the participant and surgeon experience. Three experienced surgeons performed most of the surgeries.

The technique for surgically staging EC was defined in accordance with the FIGO recommendations: hysterectomy with bilateral salpingo-oophorectomy with or without pelvic and paraaortic lymph node dissection after intraoperative frozen section in indicated cases. ${ }^{15}$ Extrafascial hysterectomy and bilateral salpingo-oophorectomy were always performed. The technique for laparoscopic hysterectomy only included total laparoscopic approaches and excluded laparoscopic assisted techniques. Patients with low-risk disease (grade 1 or 2, endometrioid histology, myometrial invasion $<50 \%$ ) were not required to undergo lymphadenectomy. In all other patients, pelvic and paraaortic lymph nodes who were enlarged or suspicious were removed, and lymphadenectomies were performed when it was technically possible. Women who did not undergo at least sampling of pelvic and paraaortic lymph nodes were considered to be incompletely surgically staged. Cytoreduction was often performed when metastases were evident. An omentectomy was performed for patients with serous and clear cell histology.

Patient clinical files and documented laparoscopy conversion to laparotomy, operative time, need for blood transfusion, intraoperative and postoperative complications, dates of surgery and discharge, and adjuvant cancer therapy (radiation, chemotherapy or hormonal therapy) were retrospectively investigated. Intraoperative injuries were quantified by number and categorized as hemorrhagic shock, visceral injury, vasculo-nerve injury, vaginal laceration and uterus laceration. Postoperative adverse events were quantified by number and categorized as reintervention, due to wound dehiscence, wound or abdominal infection, hemoperitoneum, thromboembolic events, neuropathy, ileus or bowel obstruction and incisional hernia.

Standardized pathology evaluation was done by the local pathologist, documenting the uterus weight and the number of nodes removed and the number of positive nodes at each of the three regions (left and right pelvic and paraaortic). The FIGO staging and prognostic criteria (depth of myometrial invasion, cervical involvement, lympho-vascular invasion, metastatic sites and peritoneal cytology results) were also evaluated.

Postprocedure follow-up was done 1 month postoperatively, and, then, every 4 months for the first 2 years, every 6 months for the following 3 years, and, then, annually thereafter to evaluated recurrence, treatment and survival. ${ }^{16}$ Recurrence was assessed during the study period, which means that only the first-year group completed a 5-year follow-up. Adjuvant therapy was done according to the national guidelines.

Continuous data not normally distributed were compared using the Student $t$-test for average comparisons and categorical data were compared using the Chi-squared and Fisher exact tests. To deed analysis of continuous data, it is presented also as medians with interquartile ranges (IQRs) and numbers and percentages for categorical data. A statistical analysis of patient survival was made considering two events: death or recurrence. The Kaplan-Meier test was used to analyze the time variable counted in months, counted from the date of surgery and the date of the event. The Cox-Mantel test was used in survival analysis. A $p$-value $<0.05$ was considered as statistically significant. All analyses were made using SPSS version 25 (IBM, Armonk, NY, USA).

The body mass index (BMI) was calculated as weight in kilograms divided by the square of height in meters. Obesity was considered when BMI was $\geq 30 \mathrm{~kg} / \mathrm{m} 2$.

\section{Results}

A total of 162 patients were selected for this study. 24 patients were excluded according to the criteria described above. This resulted in a final sample of 138 patients, 41 of whom underwent staging by laparoscopy and 97 who were submitted to staging by laparotomy (-Fig. 1).

The patient characteristics are shown in -Table 1. The age and BMI did not differ significantly between the groups. The median age of patients was 67 years (IQR, 60 to 74 years) and $95.7 \%$ of the patients were older than 50 . The median BMI was $30 \mathrm{Kg} / \mathrm{m} 2$ (IQR, 27 to $33 \mathrm{Kg} / \mathrm{m} 2$ ) and $48 \%$ of the included patients were obese. The distribution by surgical stage, histologic grade and histologic diagnosis was similar for the two groups (-Table 2 ).

There was no statistically significant between the two groups concerning the type of surgery, number of nodes excised or uterus weight (-Table $\mathbf{3}$ ). Lymph nodes were histologically documented from the pelvis in $73.9 \%$ $(n=34)$ of laparotomy patients and $68.8 \%(n=11)$ of laparoscopy patients $(p=0.19)$. Both paraaortic and pelvic lymph nodes were identified in $65.3 \%(n=30)$ in laparotomy patients and $43.8 \%(n=7)$ in laparoscopic patients $(p=0.68)$.

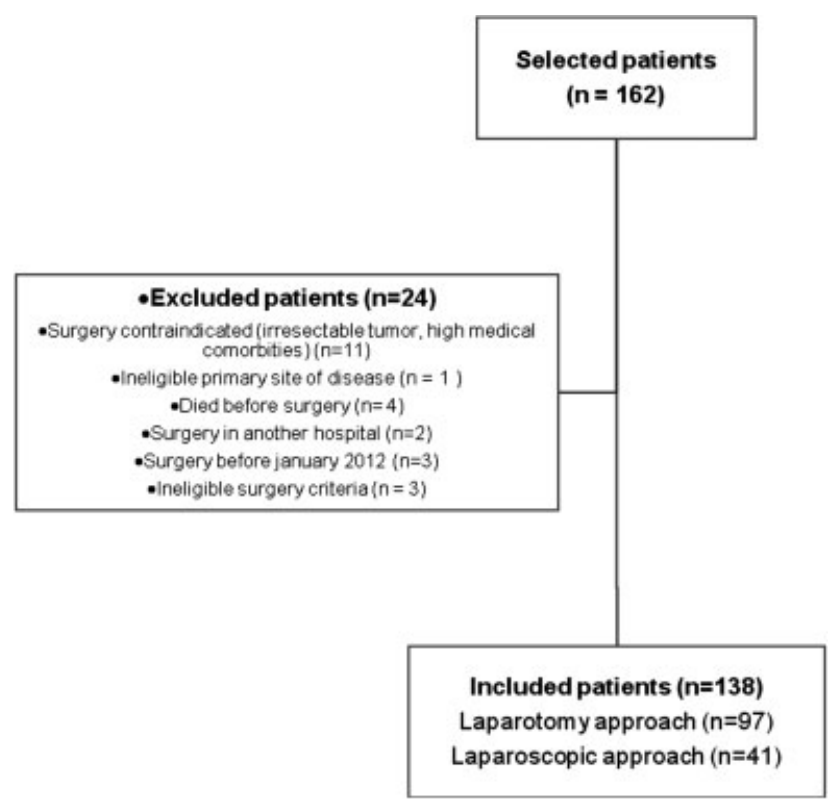

Fig. 1 Diagram of participants $(n=162)$. 
Table 1 Patient characteristics $(n=138)$

\begin{tabular}{|l|l|l|l|}
\hline & $\begin{array}{l}\text { Laparotomy } \\
(\boldsymbol{n}=\mathbf{9 7})\end{array}$ & $\begin{array}{l}\text { Laparoscopy } \\
(\boldsymbol{n}=\mathbf{4 1})\end{array}$ & $P$-value \\
\hline Age (years) & $66(59.0-74.0)$ & $68(62.0-76.0)$ & 0.32 \\
\hline $\begin{array}{l}\text { BMI } \\
\left(\mathbf{K g} / \mathrm{cm}^{2}\right)\end{array}$ & $\begin{array}{l}30.5 \\
(27.0-35.4)\end{array}$ & $\begin{array}{l}29.9 \\
(25.0-32.3)\end{array}$ & 0.26 \\
\hline Obesity (n) & $55(56.7 \%)$ & $20(48.8 \%)$ & 0.25 \\
\hline $\begin{array}{l}\text { Anterior } \\
\text { surgery (n) }\end{array}$ & $25(25.8 \%)$ & $4(9.8 \%)$ & 0.04 \\
\hline
\end{tabular}

Abbreviation: BMI, body mass index.

Table 2 Tumor characteristics $(n=138)$

\begin{tabular}{|c|c|c|c|}
\hline & $\begin{array}{l}\text { Laparotomy } \\
(n=97)\end{array}$ & $\begin{array}{l}\text { Laparoscopy } \\
(n=41)\end{array}$ & $P$-value \\
\hline \multicolumn{3}{|l|}{ Surgical stage (n) } & \multirow[t]{6}{*}{0.92} \\
\hline IA & $51(52.6 \%)$ & $25(61 \%)$ & \\
\hline IB & $22(22.7 \%)$ & $8(19.5 \%)$ & \\
\hline II & $4(4.1 \%)$ & $1(2.5 \%)$ & \\
\hline III & $17(17.5 \%)$ & $6(14.5 \%)$ & \\
\hline IV & $3(3.1 \%)$ & $1(2.5 \%)$ & \\
\hline \multicolumn{3}{|l|}{ Histologic grade (n) } & \multirow[t]{4}{*}{0.44} \\
\hline Grade 1 & $34(35.1 \%)$ & $15(36.6 \%)$ & \\
\hline Grade 2 & $39(40.2 \%)$ & $20(48.8 \%)$ & \\
\hline Grade 3 & $24(24.7 \%)$ & $6(14.6 \%)$ & \\
\hline \multicolumn{4}{|l|}{ Histologic type (n) } \\
\hline $\begin{array}{l}\text { Endometrioid } \\
\text { adenocarcinoma }\end{array}$ & $78(80.4 \%)$ & $36(87.8 \%)$ & \multirow[t]{6}{*}{0.64} \\
\hline Serous carcinoma & $9(9.3 \%)$ & $3(4.1 \%)$ & \\
\hline $\begin{array}{l}\text { Clear cell } \\
\text { carcinoma }\end{array}$ & $2(2.1 \%)$ & $0(0 \%)$ & \\
\hline Carcinosarcoma & $3(3.1 \%)$ & $3(4.1 \%)$ & \\
\hline Mixed carcinoma & $4(4.1 \%)$ & $3(4.1 \%)$ & \\
\hline Undifferentiated & $1(1 \%)$ & $0(0 \%)$ & \\
\hline
\end{tabular}

Advanced surgical stages (stage III or IV) were found in $20.6 \%$ of laparoscopy patients and $17.0 \%$ of laparotomy patients. The median operative time for the laparotomy group was 130 minutes (IQR, 105-160 minutes) and for the laparoscopy group it was 175 minutes (IQR, 130-280 minutes) $(p<0.001)$. There were 2 patients ( $4.9 \%$ of the total of laparoscopy group) who required conversion to laparotomy to complete the procedure due to poor exposure. The rates of intraoperative complications showed no difference between the 2 groups ( $4.1 \%$ for laparotomy vs $12.2 \%$ for laparoscopy, $p=0.88$ ) (-Table 4). Postoperative complications were significantly more common in laparotomy patients than in laparoscopy patients (23.7\% vs 7.2\%, respectively; $p=0.005$ ) (-Table 4 ).

The median length of stay for laparotomy patients was 7 days (IQR, 6-8 days), and the median length of stay for the laparoscopy patients was 3 days (IQR, $3-4$ days) ( $p<0.001$ ), of which 1 day preoperatively and 1 day postoperatively. There were no differences between the adjuvant treatment after surgery (-Table 5 ).

Comparing the recurrence rate, there was no significance between the surgical approaches: in laparotomy, it occurred in 5 patients and in laparoscopy, it happened in 2 patients $(5.1 \% \mathrm{~V}$ 4.9 , respectively; $p=0.50$ ). The estimated number of months of survival to recurrence was 63 months for patients undergoing laparotomy and 46 months for patients who underwent laparoscopy. When comparing the survival time to recurrence, the differences did not show statistical significance $(p=0.65)$. There were 14 deaths during follow-up: 11 from the laparotomy group and 3 from the laparoscopy one (11.3\% vs $7.3 \%$, respectively; $p=0.404$ ); none occurred in the 30-day postoperative period. Deaths were secondary to progressive stage IVB cancer in 9 cases; due to stroke in 1 case; and pulmonary infection in 2 cases. In 2 patients, the cause of the death was not accessible in the system, possibly because they occurred in a different country. The estimated number of months of survival to death was 63 and 45 months in laparotomy and laparoscopic patients, respectively. When comparing the survival time to death and given the low number of cases, the differences did not show statistical significance $(p=0.56)$.

Table 3 Surgery characteristics $(n=138)$

\begin{tabular}{|c|c|c|c|}
\hline & Laparotomy $(n=97)$ & Laparoscopy $(n=41)$ & $P$-value \\
\hline \multicolumn{3}{|l|}{ Surgery type (n) } & \multirow[t]{4}{*}{0.24} \\
\hline Total hysterectomy + bilateral salpingo-oophorectomy ${ }^{\mathrm{a}}$ & $61(62.9 \%)$ & $30(73.2 \%)$ & \\
\hline $\begin{array}{l}\text { Total hysterectomy }+ \text { bilateral salpingo-oophorectomy }+ \\
\text { pelvic and paraaortic lymphadenectomy }{ }^{\mathrm{a}}\end{array}$ & $32(34.8 \%)$ & $8(19.5 \%)$ & \\
\hline $\begin{array}{l}\text { Total hysterectomy }+ \text { bilateral salpingo-oophorectomy }+ \\
\text { pelvic lymphadenectomy }\end{array}$ & $4(2.3 \%)$ & $3(7.3 \%)$ & \\
\hline Pelvic nodes dissected & $9(6-12)$ & $9(7-11)$ & 0.22 \\
\hline Aortic nodes dissected & $3(2-4)$ & $4(1-6)$ & 0.06 \\
\hline Uterus weight (gr) & $98.0(67.0-161.0)$ & $88.0(74.3-125)$ & 0.24 \\
\hline \multicolumn{3}{|l|}{ Staging (n) } & \multirow[t]{3}{*}{0.28} \\
\hline Complete & 77 (79.4\%) & $30(73.2 \%)$ & \\
\hline Incomplete & $20(20.6 \%)$ & $11(26.8 \%)$ & \\
\hline
\end{tabular}

${ }^{a}$ with or without omentectomy. 
Table 4 Perioperative complications $(n=138)$

\begin{tabular}{|c|c|c|c|}
\hline & $\begin{array}{l}\text { Laparotomy } \\
(n=97)\end{array}$ & $\begin{array}{l}\text { Laparoscopy } \\
(n=41)\end{array}$ & $P$-value \\
\hline \multicolumn{4}{|l|}{$\begin{array}{l}\text { Intraoperative } \\
\text { complications (n) }\end{array}$} \\
\hline None & 93 (95.9\%) & $36(87.8 \%)$ & \multirow[t]{6}{*}{0.88} \\
\hline $\begin{array}{l}\text { Hemorrhagic } \\
\text { shock }\end{array}$ & $1(1 \%)$ & $0(0 \%)$ & \\
\hline Visceral injurie & $2(2.1 \%)$ & $1(2.4 \%)$ & \\
\hline $\begin{array}{l}\text { Vasculo-nerve } \\
\text { injurie }\end{array}$ & $1(1 \%)$ & $1(2.4 \%)$ & \\
\hline Uterus laceration & $0(0 \%)$ & $2(4.9 \%)$ & \\
\hline Vaginal laceration & $0(0 \%)$ & $1(2.4 \%)$ & \\
\hline $\begin{array}{l}\text { Postoperative } \\
\text { complications (n) }\end{array}$ & & & \multirow[t]{9}{*}{0.005} \\
\hline None & $74(76.3 \%)$ & $38(92.8 \%)$ & \\
\hline $\begin{array}{l}\text { Wound } \\
\text { dehiscence }{ }^{a}\end{array}$ & $10(10.3 \%)$ & $1(2.4 \%)$ & \\
\hline $\begin{array}{l}\text { Wound or } \\
\text { abdominal } \\
\text { infection a }\end{array}$ & $4(4.1 \%)$ & $1(2.4 \%)$ & \\
\hline Hemoperitoneum $^{a}$ & $1(1.0 \%)$ & $0(0 \%)$ & \\
\hline $\begin{array}{l}\text { Thromboembolic } \\
\text { events }\end{array}$ & $2(2.1 \%)$ & $0(0 \%)$ & \\
\hline Neuropathy & $0(0 \%)$ & $1(2.4 \%)$ & \\
\hline $\begin{array}{l}\text { lleus/bowel } \\
\text { obstruction }\end{array}$ & $2(2.1 \%)$ & $0(0 \%)$ & \\
\hline Incisional hernia & $4(4.1 \%)$ & $0(0 \%)$ & \\
\hline Blood transfusion (n) & $4(4.1 \%)$ & $1(2.4 \%)$ & 0.63 \\
\hline
\end{tabular}

${ }^{\text {a }}$ with need for reintervention (reoperation or readmission).

Table 5 Postoperative cancer therapy $(n=138)$

\begin{tabular}{|l|l|l|l|}
\hline & $\begin{array}{l}\text { Laparoscopy } \\
(\boldsymbol{n}=\mathbf{9 7})\end{array}$ & $\begin{array}{l}\text { Laparotomy } \\
(\boldsymbol{n}=\mathbf{4 1})\end{array}$ & -value \\
\cline { 1 - 3 } $\begin{array}{l}\text { Clinical and } \\
\text { imaging } \\
\text { surveillance only }\end{array}$ & $51(52.6 \%)$ & $27(65.8 \%)$ & 0.28 \\
\cline { 1 - 2 } & $22(22.7 \%)$ & $6(14.6 \%)$ & \\
\cline { 1 - 3 } $\begin{array}{l}\text { Radiation plus } \\
\text { chemotherapy }\end{array}$ & $12(12.4 \%)$ & $6(14.6 \%)$ & \\
\cline { 1 - 3 } Chemotherapy & $11(11.3 \%)$ & $1(2.5 \%)$ & \\
\cline { 1 - 3 } $\begin{array}{l}\text { Hormonal } \\
\text { therapy }\end{array}$ & $1(1 \%)$ & $1(2.5 \%)$ & \\
\hline
\end{tabular}

\section{Discussion}

This retrospective, single-institute study emphasized the safety and feasibility profile of laparoscopy in the surgical staging of EC when compared with the classical approach by laparotomy.

Despite the benefits of laparoscopic surgical staging, this technique is not risk-free. Potential major complications include injury to major vessels or nerves, lymphedema, and associated cellulitis. ${ }^{8}$
Due to the increasing worldwide experience in the use of laparoscopy for EC, the criteria are rapidly changing, but laparotomy remains an option, classically in those with a large uterus, metastatic disease and BMI greater than $35 \mathrm{~kg} / \mathrm{m}^{2}$, even though the decision seems to be ultimately center and surgeon-related. ${ }^{10}$

Differences in the number of lymph nodes removed between the two approaches were secondary to intraoperative decisions based on operative morbidity or another individual surgeon bias. An important potential limitation of laparoscopic EC staging is the difficulty of using this technique to dissect the paraaortic nodes. To reach this level laparoscopically, advanced skills are required, and possibly, special techniques. ${ }^{17}$ The role of comprehensive surgical staging including a systematic retroperitoneal node dissection for all patients is unclear and not consistently recommended. ${ }^{2,18}$ There is ongoing controversy over whether pelvic and paraaortic node sampling or complete lymph node dissection (LND) should be performed. ${ }^{19}$ The status of both the pelvic and paraaortic lymph nodes should be assessed intraoperatively in intermediate/high risk of recurrence patients, as advised by the FIGO surgical and pathologic staging system. ${ }^{20}$ However, the type and extent of LND were not specified.

Advanced surgical stage was detected in about $1 / 6$ of the patients staged by laparoscopy and all these patients had a complete surgical staging performed, which may lead one to assume that the laparoscopic approach is effective in the advanced stages of endometrial carcinoma.

The laparotomy group included all the patients that were initially approached by diagnostic laparoscopy, according to local protocol, and that had their staging performed by laparotomy due to a frozen pelvis, for instance. That is probably the reason why the rate of conversion was lower than in other studies, as well as the fact that all laparoscopic surgeries were performed by only two experienced surgeons. 2,10,12

Overall results in this study coincide with those in literature: no statistically significant difference in the rate of perioperative death, blood transfusion, visceral or vascular injury; fewer severe postoperative adverse events in the laparoscopy group and similar rates of intraoperative complications. Although operative time was longer for laparoscopy, the hospital stay was shorter compared with laparotomy. ${ }^{9,10,12,13,21-23}$ A limitation of this study is that authors cannot draw definitive conclusions about survival or recurrence-free interval because, in most cases, the follow-up period was too short, and the number of cases was small.

Successful laparoscopy, being a less invasive procedure, results in less pain, faster recovery and a significantly reduced length of hospital stay.

This study indicates that surgical staging of EC can be performed using laparoscopy without increased intraoperative injuries, with fewer postoperative complications, and with a shorter hospital stay. This makes laparoscopy worth the extra operative time and the surgeon's investment in training. ${ }^{10}$

It is not possible to recommend a single systematic approach to the surgical staging of EC nowadays, but laparoscopy is undoubtedly an excellent option and possibly the 
preferable choice in a large percentage of cases. This study strengthens the possibility of opting for laparoscopy in EC staging for selected patients. Nevertheless, an individual assessment of each patient is warranted, even for experienced laparoscopic surgeons, and the risks and benefits of laparoscopic surgical staging will continue to influence which is the best operative approach for a given patient. ${ }^{10}$

Laparoscopic staging should only be performed by a surgeon with experience in laparoscopic hysterectomy and lymph node sampling.

Despite the many benefits that the laparoscopic approach exhibits in the surgical staging of EC, there are still a very limited number of departments worldwide that are fully prepared to offer this kind of treatment approach. This study reveals only partially the difficulty and limitations of the technique and serves as base for comparison and/or inspiration to other centers that are still developing their ability to opt for the minimal invasive approach in such situations.

\section{Conclusion}

Laparoscopic surgical staging for EC has been shown to be safe and feasible with an experienced team. This study demonstrated the safety of the laparoscopic approach, with lower postoperative complication rates and shorter hospital stays, when compared with the approach by laparotomy.

\section{Contributors}

All authors declare to have contributed to the project conception, to the data analysis and interpretation, to the writing of the manuscript, to the relevant critical review of the intellectual content, and to the final approval of the version to be published.

\section{Conflicts to Interest}

The authors declare that there were no conflicts of interest.

\section{Acknowledgments}

The authors would like to recognize Prof. Ana Mouraz, who contributed to statistical data analysis.

\section{References}

1 World Cancer Research Fund Global Network. Endometrial Cancer 2013 Report. Accessed in May 17, 2019, https://www.wcrf.org/ sites/default/files/Endometrial-Cancer-2013-Report.pdf

2 Van den Bosch A, Mertens H. Implementation of laparoscopic surgery for endometrial cancer: work in progress. Facts Views Vis ObGyn 2016;8(01):23-30

3 Lee CL, Kusunoki S, Huang KG, Wu KY, Huang CY, Yen CF. Longterm survival outcomes of laparoscopic staging surgery in treating endometrial cancer: 20 years of follow-up. Taiwan J Obstet Gynecol 2016;55(04):545-551 10.1016/j.tjog.2016.04.035

4 Siegel R, Ward E, Brawley O, Jemal A. Cancer statistics, 2011: the impact of eliminating socioeconomic and racial disparities on premature cancer deaths. CA Cancer J Clin 2011;61(04):212-236 10.3322/caac.20121
5 Rungruang B, Olawaiye AB. Comprehensive surgical staging for endometrial cancer. Rev Obstet Gynecol 2012;5(01):28-34 10.3909/riog0177

6 Pecorelli S. Revised FIGO staging for carcinoma of the vulva, cervix, and endometrium. Int J Gynaecol Obstet 2009;105(02): 103-104 10.1016/j.ijgo.2009.02.012

7 Announcement: FIGO stages: 1988 revision: definitions of the clinical stages in carcinoma of the vulva. Gynecol Oncol 1989;35:125-126

8 Practice Bulletin No. Practice Bulletin No. 149: Endometrial cancer. Obstet Gynecol 2015;125(04):1006-1026 10.1097/01. AOG.0000462977.61229.de

9 Asher R, Obermair A, Janda M, Gebski V. Disease-free and survival outcomes for total laparoscopic hysterectomy compared with total abdominal hysterectomy in early-stage endometrial carcinoma: a meta-analysis. Int J Gynecol Cancer 2018;28(03): 529-538 10.1097/IGC.0000000000001199

10 Walker JL, Piedmonte MR, Spirtos NM, et al. Laparoscopy compared with laparotomy for comprehensive surgical staging of uterine cancer: Gynecologic Oncology Group Study LAP2. J Clin Oncol 2009;27(32):5331-5336 10.1200/JCO.2009.22.3248

11 Galaal K, Bryant A, Fisher AD, Al-Khaduri M, Kew F, Lopes AD. Laparoscopy versus laparotomy for the management of early stage endometrial cancer. Cochrane Database Syst Rev 2012; (09):CD006655 10.1002/14651858.CD006655.pub2

12 Mourits MJ, Bijen CB, Arts HJ, et al. Safety of laparoscopy versus laparotomy in early-stage endometrial cancer: a randomised trial. Lancet Oncol 2010;11(08):763-771 10.1016/S1470-2045(10)70143-1

13 Janda M, Gebski V, Brand A, et al. Quality of life after total laparoscopic hysterectomy versus total abdominal hysterectomy for stage I endometrial cancer (LACE): a randomised trial. Lancet Oncol 2010;11(08):772-780 10.1016/S1470-2045(10)70145-5

14 Kurman RJ, Carcangiu ML, Herrington CS, Young RH, Eds. WHO classification of tumours of the female reproductive organs. 4th ed. Geneva: World Health Organization; 2014

15 International Federation of Gynecology and Obstetrics. FIGO News: corpus cancer staging. Int J Gynaecol Obstet 1989;28:189-190

16 Salani R, Backes FJ, Fung MF, et al. Posttreatment surveillance and diagnosis of recurrence in women with gynecologic malignancies: Society of Gynecologic Oncologists recommendations. Am J Obstet Gynecol 2011;204(06):466-478 10.1016/j.ajog.2011.03.008

17 Dowdy SC, Aletti G, Cliby WA, Podratz KC, Mariani A. Extraperitoneal laparoscopic para-aortic lymphadenectomy-a prospective cohort study of 293 patients with endometrial cancer. Gynecol Oncol 2008;111(03):418-424 10.1016/j.ygyno.2008.08.021

18 Ribeiro R, Silva DP. Estadiamento cirúrgico do cancro do endométrio. Acta Obstet Ginecol Port 2010;4:88-100

19 Cohn ED. Endometrial carcinoma: Clinical features and diagnosis. Accessed in May 17, 2019, https://www.uptodate.com/contents/ endometrial-carcinoma-staging-and-surgical-treatment

20 Tanaka T, Terai Y, Hayashi S, et al. Comparison between laparoscopy and laparotomy in systematic para-aortic lymphadenectomy for patients with endometrial cancer: a retrospective multicenter study. J Gynecol Surg 2017;33(03):105-110 10.1089/gyn.2016.0101

21 de la Orden SG, Reza MM, Blasco JA, Andradas E, Callejo D, Pérez T. Laparoscopic hysterectomy in the treatment of endometrial cancer: a systematic review. J Minim Invasive Gynecol 2008;15 (04):395-401 10.1016/j.jmig.2008.04.018

22 Janda M, Gebski V, Davies LC, et al. Effect of total laparoscopic hysterectomy vs total abdominal hysterectomy on disease-free survival among women with stage i endometrial cancer: a randomized clinical trial. JAMA 2017;317(12):1224-1233 10.1001/jama. 2017.2068

23 Walker JL, Piedmonte MR, Spirtos NM, et al. Recurrence and survival after random assignment to laparoscopy versus laparotomy for comprehensive surgical staging of uterine cancer: Gynecologic Oncology Group LAP2 Study. J Clin Oncol 2012;30 (07):695-700 10.1200/JCO.2011.38.8645 